\title{
Sjögren Syndrome without Focal Lymphocytic Infiltration of the Salivary Glands
}

\author{
Rohan Sharma, Kaustubh S. Chaudhari, Biji T. Kurien, Kiely Grundahl, Lida Radfar, \\ David M. Lewis, Christopher J. Lessard, He Li, Astrid Rasmussen, Kathy L. Sivils, \\ and R. Hal Scofield (D)
}

ABSTRACT. Objective. Primary Sjögren syndrome (SS) is characterized by a focal lymphocytic infiltrate in exocrine glands. We describe patients who lacked this key feature.

Methods. We evaluated patients with sicca in a comprehensive clinic at which medical, dental, and ophthalmological examinations were performed. All subjects underwent a minor salivary gland biopsy with focus score calculation. Extraglandular manifestations were also determined. We categorized subjects as high, intermediate, or low in terms of expression of interferon (IFN)-regulated genes.

Results. About 20\% (51 of 229, 22\%) of those classified as having primary SS had a focus score of zero. Compared to those with anti-Ro positivity and a focus score $>1.0$, the patients with focus score of zero (who by classification criteria must be anti-Ro-positive) were statistically less likely to have anti-La (or SSB) and elevated immunoglobulin, as well as less severe corneal staining. The focus score zero patients were less likely to have elevated expression of IFN-regulated genes in peripheral blood mononuclear cells than anti-Ro-positive SS patients with a focal salivary infiltrate.

Conclusion. There are only a few clinical differences between patients with primary SS with focus score zero and those with both anti-Ro and a focus score $>1.0$. The small subset of focus score zero patients tested did not have elevated expression of IFN-regulated genes, but did have systemic disease. Thus, extraglandular manifestations are perhaps more related to the presence of anti-Ro than increased IFN. This may have relevance to pathogenesis of SS. (First Release September 15 2019; J Rheumatol 2020;47:394-9; doi:10.3899/jrheum.181443)

Key Indexing Terms:

PRIMARY SJÖGREN SYNDROME

INTERFERON

AUTOANTIBODIES

From the Arthritis and Clinical Immunology Program, Oklahoma Medical Research Foundation, Oklahoma City, Oklahoma; Department of Neurology, University of Arkansas Medical Sciences Center, Little Rock, Arkansas; Medical and Research Services, Oklahoma City Department of Veterans Affairs Medical Center; Departments of Medicine and Pathology, University of Oklahoma Health Sciences Center; College of Dentistry, University of Oklahoma Health Sciences Center, Oklahoma City, Oklahoma, USA.

Supported in part by US National Institutes of Health grants AR053483, AR060804, AI0822714, and GM104938, and US Department of Veterans Affairs grant BX001451.

R. Sharma, MBBS, Arthritis and Clinical Immunology Program, Oklahoma Medical Research Foundation, Department of Neurology, University of Arkansas Medical Sciences Center; K.S. Chaudhari, MBBS, Medical and Research Services, Oklahoma City Department of Veterans Affairs Medical Center; B.T. Kurien, PhD, Arthritis and Clinical Immunology Program, Oklahoma Medical Research Foundation, Medical and Research Services, Oklahoma City Department of Veterans Affairs Medical Center, Departments of Medicine and Pathology, University of Oklahoma Health Sciences Center; K. Grundahl, BS, Arthritis and Clinical Immunology Program, Oklahoma Medical Research Foundation; L. Radfar, DDS, College of Dentistry, University of Oklahoma Health Sciences Center; D.M. Lewis, DDS, College of Dentistry, University of Oklahoma Health Sciences Center; C.J. Lessard, PhD, Arthritis and Clinical Immunology Program, Oklahoma Medical Research Foundation; H. Li, PhD, Arthritis and Clinical Immunology Program, Oklahoma Medical Research Foundation (currently Human Genome Sequencing Center, Baylor College of Medicine, Houston, Texas); A. Rasmussen, MD, PhD, Arthritis and Clinical Immunology Program, Oklahoma Medical Research Foundation; K.L. Sivils, PhD, Arthritis and Clinical Immunology Program, Oklahoma Medical Research Foundation; R.H. Scofield, MD, Arthritis and Clinical Immunology Program, Oklahoma Medical Research Foundation, Medical and Research Services, Oklahoma City Department of Veterans Affairs Medical Center, Departments of Medicine and Pathology, University of Oklahoma Health Sciences Center.

Address correspondence to Dr. R.H. Scofield, Oklahoma Medical Research Foundation, 825 NE 13th St., Oklahoma City, Oklahoma 73104, USA. E-mail: hal-scofield@omrf.ouhsc.edu

Accepted for publication May 1, 2019.

Sjögren syndrome (SS) is a chronic autoimmune disease characterized by lymphocytic infiltration of exocrine glands. Salivary and lacrimal gland involvement presenting as sicca syndrome is the most common manifestation of SS. Involvement of other exocrine glands such as those of respiratory, gastrointestinal, and genitourinary tracts can be seen concomitantly with SS sicca ${ }^{1}$. Extraglandular manifestations of the disease include arthralgia, arthritis, Raynaud phenomenon, lymphadenopathy, small airway disease, systemic vasculitis, interstitial nephritis, splenomegaly, myositis, peripheral neuropathy, and lymphoma ${ }^{2}$. The disease burden of SS in the United States is around 2-3 million patients, making it the second most prevalent inflammatory rheumatological disease ${ }^{3}$.

Focal lymphocytic infiltration of salivary glands and anti-Ro/SSA serum autoantibodies are the cardinal features of SS and are part of the current classification criteria ${ }^{4,5}$. Focal lymphocytic infiltration is measured by focus score, 
defined as the number of mononuclear cell infiltrates containing at least 50 inflammatory cells per $4 \mathrm{~mm}^{2}$ of glandular section. A focus score of 1 or greater is considered positive.

All the patients with primary SS in our large cohort underwent minor salivary gland biopsy and histological examination; we found that a significant percentage had a focus score of zero. Thus, these patients lacked one of the 2 cardinal features of SS. We investigated the differences (if any) between the patients with primary SS with focus score zero and those with non-zero focus scores.

\section{MATERIALS AND METHODS}

We evaluated individuals with sicca in the Oklahoma Medical Research Foundation (OMRF) Sjögren's Syndrome Research Clinic ${ }^{6,7,8,9}$. Subjects were evaluated by a rheumatologist, an ophthalmologist (or optometrist), and a dentist. The dentist performed an oral examination consisting of measurement of stimulated and timed whole unstimulated salivary flow, a lip biopsy, and collection and storage of saliva. Evaluation did not include sialography or scintigraphy. The ocular specialist performed ocular surface staining with Lissamine green and fluorescein, an unanesthetized Schirmer I test, and collection and storage of tears. The ocular vital dye score was determined using the quantitative dot-counting method according to both the van Bijsterveld ${ }^{10}$ and ocular staining score methods ${ }^{11}$, rather than by descriptive features. A physician completed a detailed history and physical examination, including general medical, rheumatological, and neurological evaluations. Blood samples were collected for extraction and storage of DNA, RNA, and serum. Anti-Ro (SSA) and anti-La (SSB) autoantibodies were determined by multiple methods ${ }^{6}$. All patients were tested for rheumatoid factor, antinuclear antibodies, and autoantibodies associated with other connective tissue disorders. Subjects also had hepatitis C serology, complete blood count with differential, immunoglobulin profile, and urinalysis. If patients gave a history of a past diagnosis of rheumatoid arthritis, mixed connective tissue disease, systemic sclerosis, myositis, primary biliary cirrhosis, multiple sclerosis, or systemic lupus erythematosus, classification criteria for these illnesses were specifically ascertained by history, medical record review, and testing for the corresponding autoantibodies. Minor salivary gland pathology was determined by a dental pathologist with calculation of focus score following the method of Daniels ${ }^{12}$ as follows: number of lymphocytic foci adjacent to normal-appearing acini with $>50$ cells observed divided by area studied $\left(\mathrm{mm}^{2}\right) \times 4 \mathrm{~mm}^{2}$. As delineated in the recent guidelines ${ }^{13}$, which we followed, focus score calculation does not take into account nonfocal lymphocytic infiltration, which may be present despite a focus score of zero.

Subjects were classified according to the American-European Consensus Group (AECG) and the American College of Rheumatology/European League Against Rheumatism (ACR/EULAR) criteria for $\mathrm{SS}^{4,5,14,15}$, both of which require one of anti-Ro/La or a focus score $>1.0$. Thus, all subjects classified as having SS with a focus score $<1.0$ must have anti-Ro under the ACR/EULAR criteria or either anti-Ro or anti-La under the AECG criteria. Clinical diagnosis of SS is by expert opinion and does not rely on these classification criteria, which are formulated for research purposes only. All subjects had a clinical diagnosis of SS made at the time of the evaluation in the OMRF Sjögren's Syndrome Research Clinic.

We determined mRNA expression by microarray, as described ${ }^{16,17}$. We categorized individual patients as having high, intermediate, or low interferon (IFN)-regulated gene expression by unsupervised hierarchical clustering using centroid linkage with uncentered correlation ${ }^{18}$. We used Cluster $3.0^{18}$ for clustering of gene expression and visualized these results in Java TreeView ${ }^{19}$.

We compared the patients with focus score zero with those with focus scores of $<1$ and $\geq 1$, regarding classification criteria and extraglandular manifestations, using SAS software for data analysis. We used chi-square or Fisher's exact test for comparisons between the groups. Understanding the need for correction for multiple comparisons we agreed upon an $\alpha$ of 0.005 for statistical significance, so $p$ values $<0.005$ were considered statistically significant. Because this was an investigative study, we used the $\alpha$ of 0.005 rather than Bonferroni correction, which is more conservative in its estimation and therefore more likely to give false-negative results. Given the a priori hypothesis for the IFN-regulated gene expression studies and the small number of statistical tests, no correction for multiple comparisons was made.

All procedures were approved by the Oklahoma Medical Research Foundation Institutional Review Board (no. 11-03). Each participant provided written informed consent prior to entering the study.

\section{RESULTS}

Among 229 subjects classified as having primary SS, we found 51 with focus score zero ( $\mathrm{FS}=0,22 \%), 167$ with focus score positive ( $\mathrm{FS} \geq 1,73 \%)$, and 11 with focus score between 0 and $1(0<\mathrm{FS}<1,5 \%)$. No patient with a focus score of zero had a gland replaced by fibrosis, and all subjects had adequate tissue for examination and calculation of focus score. All subjects with a focus score $<1$ had anti-Ro/SSA in their sera. This is, of course, by definition of the criteria, which require either a focus score $\geq 1.0$ or autoantibodies. For focus score-positive patients, we included only those with positive anti-Ro for study to match with the focus score zero patients, all of whom have anti-Ro. Nonetheless, subjects with $\mathrm{FS}=0$ were statistically less likely to have anti-La (or SSB) detected than subjects with FS $\geq 1(10 / 51$, $19.6 \%$ vs $98 / 167,58.7 \%$, respectively; $p<0.001$ ). There was a statistical trend for only the $0<\mathrm{FS}<1$ subjects to have less anti-La compared to $\mathrm{FS} \geq 1$ subjects (Table 1 ).

We next examined the presence or absence of the classification criteria (Table 1). When considering the AECG sicca criteria, all subjects answered positively to at least 1 dry mouth and 1 dry eye question. Thus, there was no statistical difference in the presence of sicca symptoms among the groups. Similarly, there was no difference in the presence of an abnormal Schirmer test among the 3 groups; however, abnormal Lissamine green corneal staining was statistically more common among subjects with $\mathrm{FS} \geq 1.0$ compared to those with FS of zero ( $p=0.0032$; Table 1$)$. Whole unstimulated salivary flow did not differ between the 3 groups.

Comparing disease manifestations not identified in the classification criteria but part of the Sjögren's Syndrome Disease Activity Index (SSDAI) ${ }^{20,21}$, we found only a few differences between the groups. Elevated serum IgG, a manifestation within the biological domain of the SSDAI, was significantly higher in focus score-positive subjects compared to those with focus score zero $(\mathrm{p}=0.0003$; Table ). Otherwise, neither salivary gland enlargement nor other extraglandular manifestations differed among the 3 groups (Table 2).

Previous reports show that increased expression of IFN-regulated genes in peripheral blood cells is highly correlated with the presence of anti-Ro among patients with

Personal non-commercial use only. The Journal of Rheumatology Copyright (C) 2020. All rights reserved. 
Table 1. Classification criteria among subjects with primary Sjögren syndrome with a focus score $>1$ (FS $>1)$, a focus score of zero $(\mathrm{FS}=0)$, and a focus score between zero and $1(0<\mathrm{FS}<1)$. All subjects answered positively at least 1 dry eye question and 1 dry mouth question from the AECG criteria.

\begin{tabular}{lccccc}
\hline & $\begin{array}{c}\mathrm{FS} \geq 1, \\
\mathrm{n}=167\end{array}$ & $\begin{array}{c}\mathrm{FS}=0, \\
\mathrm{n}=51\end{array}$ & $\begin{array}{c}0<\mathrm{FS}<1, \\
\mathrm{n}=11\end{array}$ & $\geq 1$ vs 0 & $\geq 1$ vs $<1$ \\
\hline Anti-La/SSB $(\%)$ & $98(59)$ & $10(20)$ & $4(36)$ & $<0.0001$ & 0.145 \\
WUSF (\%) & $103^{*}(63)$ & $36(71)$ & $6(55)$ & 0.309 & 0.160 \\
Schirmer test (\%) & $85^{* *}(52)$ & $18 \dagger(36)$ & $6(55)$ & 0.05 & 0.140 \\
Lissamine green (\%) & $115+(72)$ & $25(50)$ & $8(73)$ & 0.0032 & 0.152 \\
\hline
\end{tabular}

*Not performed in 4 subjects; **not performed in 3; †not performed in 1; $\neq$ not performed in 7 . WUSF: whole unstimulated salivary flow; AECG: American-European Consensus Group.

Table 2. Manifestations from the European Sjögren's Syndrome Disease Activity Index among subjects with primary Sjögren syndrome with a focus score $>1$ ( FS $>1$ ), a focus score of zero (FS $=0$ ), and a focus score between zero and $1(0<\mathrm{FS}<1)$.

\begin{tabular}{|c|c|c|c|c|c|}
\hline Manifestation & $\begin{array}{l}\mathrm{FS} \geq 1, \\
\mathrm{n}=167\end{array}$ & $\begin{array}{l}\mathrm{FS}=0 \\
\mathrm{n}=51\end{array}$ & $\begin{array}{c}0<\mathrm{FS}<1 \\
\mathrm{n}=11\end{array}$ & $>1$ vs 0 & $>1$ vs $<1$ \\
\hline Parotid & 36 & 9 & 0 & 0.558 & 0.150 \\
\hline Submandibular & 21 & 9 & 0 & 0.349 & 0.150 \\
\hline Lymphadenopathy & 8 & 4 & 0 & 0.179 & 0.448 \\
\hline Constitutional & 50 & 22 & 3 & 0.07 & 0.174 \\
\hline Peripheral neuropathy & 51 & 14 & 4 & 0.690 & 0.230 \\
\hline Persistent cough & 50 & 17 & 3 & 0.62 & 0.264 \\
\hline Arthralgia & 105 & 42 & 8 & 0.0094 & 0.232 \\
\hline Arthritis* & 12 & 4 & 1 & 0.231 & 0.424 \\
\hline Arthritis** & 21 & 6 & 0 & 0.889 & 0.293 \\
\hline $\mathrm{RP}^{* *}$ & 52 & 14 & 2 & 0.633 & 0.260 \\
\hline Leukopenia & 19 & 5 & 1 & 0.763 & 0.420 \\
\hline Neutropenia & 0 & 0 & 0 & NA & NA \\
\hline Lymphopenia & 7 & 2 & 1 & 0.311 & 0.370 \\
\hline Thrombocytopenia & 2 & 1 & 0 & 0.414 & 0.822 \\
\hline Hyper $\operatorname{IgG} * * *$ & 61 & 5 & 3 & 0.0003 & 0.114 \\
\hline Hyper IgA & 26 & 7 & 3 & 0.759 & 0.177 \\
\hline Hyper IgM & 28 & 9 & 1 & 0.883 & 0.311 \\
\hline Low C3 & 0 & 0 & 0 & NA & NA \\
\hline Low C4 & 7 & 2 & 0 & 0.311 & 0.674 \\
\hline Other antibodies & 51 & 10 & 3 & 0.133 & 0.253 \\
\hline Hypo IgG & 5 & 2 & 0 & 0.307 & 0.674 \\
\hline
\end{tabular}

* Documented in history and physical examination by physician. ** Self-reported on questionnaire. *** $20 \mathrm{~g} / 1 \mathrm{used}$ as the demarcation for an elevated value because in the biological domain of the SSDAI, a serum IgG level $>20 \mathrm{~g} / 1$ is considered positive. The biological domain is considered active if the serum IgG level is above this concentration. SSDAI: Sjögren's Syndrome Disease Activity Index; RP: Raynaud phenomenon; NA: not applicable.

primary $\mathrm{SS}^{16,17,22}$. We hypothesized that this might not be the case among those with anti-Ro but no salivary gland mononuclear cell infiltrate. Indeed, we found that subjects with focus score zero were less likely to have high expression of IFN-regulated gene than anti-Ro positive subjects with a focus score $\geq 1.0$ (Table 3 ). We had peripheral blood gene expression data for 6 of the 47 subjects with a focal score of zero, and none clustered with the high-IFN group. Among those with a focal score $\geq 1$ and anti-Ro positivity, 31 of 47 were in the high-IFN group by cluster analysis ( $\mathrm{p}=0.001$, Fisher's exact test). Four of the anti-Ro-positive subjects with focus score zero had low IFN-regulated gene expression and 2 had intermediate expression by the cluster analyses. Meanwhile, among the anti-Ro-positive comparison group of subjects with focus score $\geq 1$, only 15 had intermediate and 5 had low expression of IFN-regulated genes in peripheral blood cells (Table 3 ).

\section{DISCUSSION}

Focus score is the quantitative measure of focal sialadenitis, and along with serum anti-Ro antibodies is the cardinal feature of SS. Presence of one of them is required to classify 
Table 3. Interferon-regulated gene expression categorized by unsupervised hierarchical clustering among subjects with primary Sjögren syndrome, some with a focus score (FS) $>1$ on minor salivary gland pathology and some with a focus score of zero.

\begin{tabular}{lccc}
\hline & \multicolumn{3}{c}{ Interferon-regulated Gene Expression } \\
& High & Intermediate & Low \\
\hline Anti-Ro, $\mathrm{FS}=0, \mathrm{n}=6$ & $0 * \dagger$ & 2 & 4 \\
Anti-Ro, $\mathrm{FS} \geq 1, \mathrm{n}=47$ & 31 & 15 & 5 \\
\hline
\end{tabular}

All subjects had anti-Ro. Gene expression analysis was performed on a random sample from subjects with $\mathrm{FS}=0$ and $\mathrm{FS}>1$. $* \mathrm{p}=0.001$ comparing high versus low/intermediate. $\uparrow \mathrm{p}=0.02$ comparing distribution across high, intermediate, and low interferon-regulated gene expression.

patients in a research setting, while a diagnosis of the disease is made on clinical grounds. We found that the 2 subgroups with and without focal infiltration were not clinically different, other than having higher degree of corneal staining with Lissamine green, serum anti-La antibodies, and elevated $\mathrm{IgG}$ in patients with $\mathrm{FS} \geq 1$. Hypergammaglobulinemia, elevated IgG, and serum anti-La antibodies are highly associated with the presence of anti-Ro ${ }^{23}$. Higher degree of Lissamine green staining without significantly different Schirmer test results in these patients points to a greater degree of corneal involvement even in the absence of markedly different tear production. This may be due to an alteration in protein secretion in tears, causing a qualitative loss of function.

Few studies have analyzed patients with SS without focal sialadenitis. These studies found associations of high focus score with clinical disease manifestations, but generally these studies have parsed patients with SS as focus score above 3 or 4 and $<3$ or 4 . For instance, a recent study found that a focus score $>4.0$ was associated with interstitial lung disease $^{24}$. Other work found associations of focus scores above 3 with lymphoma ${ }^{25}$. A longitudinal study found focus score $\geq 1.0$ was associated with worsening Schirmer test results $^{26}$. A study of 265 subjects with SS showed an association of positive focus score with stimulated salivary flow as well as decayed/missed/filled (DMF) teeth ${ }^{27}$. We did not examine stimulated salivary flow or DMF teeth. Carubbi and colleagues $^{28}$ examined a large group of patients $(n=794)$, of whom $72(19 \%)$ had a focus score of zero. These investigators found a number of differences between subjects with focus score zero and those with a focus score $\geq 1.0$ including xerostomia, salivary gland enlargement, hematological involvement, central nervous system involvement, and hypergammaglobulinemia. However, no correction for multiple comparisons was made in that study, which, given the lack of an a priori hypothesis concerning any differences between the groups, we thought necessary to perform. Examining the results from Carubbi, et al, we found that only hypergammaglobulinemia and hematological involvement remained statistically significant after multiple corrections. Using univariate logistic regression, Carubbi, et al found focus score $\geq 1$ was associated with lymphoma ${ }^{28}$. We did not have enough patients with lymphoma (only 1 in our cohort) to make any assessment. Thus, our study and previous ones comparing subjects with and without a positive focus score are largely in agreement, especially considering that hypergammaglobulinemia and elevated $\mathrm{IgG}$ are generally correlative.

Our findings have implications for clinical diagnosis of SS. Diagnosis is inherently difficult because it requires multiple specialties, and it is often difficult to find expertise for SS in a dentist, ophthalmologist, and pathologist at one center. Because the FS $\geq 1$ and $\mathrm{FS}=0$ groups are not remarkably different regarding clinical manifestations, in the presence of sicca symptoms with serum anti-Ro antibody, a clinical diagnosis of SS can be made essentially without the need for tissue biopsy. However, there will remain the subset of seronegative patients with SS who may require a salivary gland biopsy for clinical diagnosis. At our institution, we would rarely make a diagnosis without one of anti-Ro or focal lymphocytic infiltration of salivary glands. Others may not take this approach, and instead make a clinical diagnosis without salivary gland pathology even in the absence of anti-Ro. The research classification will continue to require one of salivary gland biopsy or serum autoantibodies concomitant with the clinical findings.

These clinical findings, along with differences in expression of IFN-related genes, have even greater implications regarding the pathogenesis of the disease. First, manifestation of sicca syndrome without focal infiltration of exocrine glands points to another pathology of gland dysfunction without gland destruction, perhaps antimuscarinic 3 receptor autoantibodies or altered expression of aquaporin molecules. Clearly, these patients without focal infiltrates do not have immune-mediated destruction of the salivary glands.

Second, the difference in IFN-regulated gene expression between the 2 groups delineates differences in underlying pathogenesis. Previous investigations found that increased expression of IFN-regulated genes in SS is highly related to anti-Ro positivity. However, we did not find a high degree of expression of this set of genes among the patients with anti-Ro but with no focal salivary gland infiltrate. Unsupervised hierarchical clustering analyses showed a statistically significant lower expression of IFN-regulated genes among anti-Ro-positive, focus score zero SS subjects compared to anti-Ro-positive with a focal infiltrate (Table 3 ). One possibility is that cells infiltrating the salivary gland are the source of IFN that is driving expression of genes in peripheral blood cells. The data are clear that the salivary glands are a site of development of lymphocytes and that B cells infiltrating the salivary gland produce anti-Ro ${ }^{29,30}$. These cells may also serve as antigen-presenting cells and produce IFN. Alternatively, IFN produced in some other location could be critical to the production of anti-Ro as well

Personal non-commercial use only. The Journal of Rheumatology Copyright @ 2020 . All rights reserved. 
as to development of the lymphocytic salivary gland infiltrate that characterizes the disease. Finally, there could be factors such as genetics of genes such as $O A S I^{17}$ that influence all 3 factors of anti-Ro, IFN production, and infiltration of the gland.

SS can be divided into those with only exocrine gland features versus those that also have systemic or extraglandular features. Data suggest that the presence of anti-Ro identifies the latter group ${ }^{31}$. The FS $=0$, anti-Ropositive patients had a similar degree of extraglandular manifestations compared to the group with focus score $\geq 1.0$ and anti-Ro. Thus, extraglandular disease is associated with anti-Ro regardless of the presence of focal sialadenitis. However, this was not the case for increased expression of IFN-regulated genes, which was not found among FS $=0$ patients despite the presence of extraglandular manifestations. Thus, anti-Ro, not expression of IFN-regulated genes, is the correlate of extraglandular manifestations. Because almost all subjects had no previous diagnosis of SS, medications that might alter IFN, including hydroxychloroquine, were not prescribed.

There are several limitations to our study. We had only a small number of subjects in whom we studied expression of IFN-regulated genes in peripheral blood cells. That is, this was a sample of convenience, so our results and conclusions must be considered preliminary. We do not have longitudinal data. Further, we do not have reliable data concerning the onset of disease, which is difficult to ascertain when talking to patients, many of whom have had sicca for years. Perhaps subjects with focal score of zero have early-stage disease and will develop focal lymphocytic infiltration over time. Our study did not address whether pathological findings might change over the course of the illness, although studies of sequential biopsies have not shown changed pathology 32 . Minor salivary gland histopathology results are variable in a given subject ${ }^{33}$; more extensive examination of multiple tissue sections might have revealed focal infiltration in some $\mathrm{FS}=0$ subjects. Finally, pathology findings in the minor salivary glands may not reflect pathology in the major salivary glands. We did not examine the major salivary glands in our cohort.

A significant fraction of patients coming to a comprehensive sicca evaluation clinic who were classified as having primary SS had no focal infiltrate upon pathological examination of minor salivary gland biopsy specimens. These subjects had only a few clinical differences compared to those with both anti-Ro and a focus score $\geq 1$. There were fewer signs of severe dry eyes among the patients who were anti-Ro-positive and focus score-negative. In addition, we found statistically less anti-La as well as fewer elevated immunoglobulin levels in these subjects. These serological findings are of interest because both factors are highly associated with the presence of anti-Ro. In addition, we found the subjects with primary SS who had no focal infiltrate but did have anti-Ro positivity did not have elevated expression of IFN-regulated genes, another characteristic highly correlated with anti-Ro. Thus, these patients who were focus score-negative and anti-Ro-positive differed from patients with focus score $\geq 1$ and who were anti-Ro-positive in interesting ways that might shed light on aspects of the pathogenesis of SS.

\section{REFERENCES}

1. Fox RI. Sjogren's syndrome. Lancet 2005;366:321-31.

2. Al-Hashimi I, Khuder S, Haghighat N, Zipp M. Frequency and predictive value of the clinical manifestations in Sjogren's syndrome. J Oral Pathol Med 2001;30:1-6.

3. Helmick CG, Felson DT, Lawrence RC, Gabriel S, Hirsch R, Kwoh $\mathrm{CK}$, et al. Estimates of the prevalence of arthritis and other rheumatic conditions in the United States. Part I. Arthritis Rheum 2008;58:15-25.

4. Vitali C, Bombardieri S, Jonsson R, Moutsopoulos HM, Alexander EL, Carsons SE, et al. Classification criteria for Sjogren's syndrome: A revised version of the European criteria proposed by the American-European Consensus Group. Ann Rheum Dis 2002;61:554-8

5. Shiboski CH, Shiboski SC, Seror R, Criswell LA, Labetoulle M, Lietman TM, et al; International Sjögren's Syndrome Criteria Working Group. 2016 American College of Rheumatology/European League Against Rheumatism classification criteria for primary Sjögren's syndrome: a consensus and data-driven methodology involving three international patient cohorts. Arthritis Rheumatol 2017;69:35-45.

6. Rasmussen A, Ice JA, Li H, Grundahl K, Kelly JA, Radfar L, et al. Comparison of the American-European Consensus Group Sjogren's syndrome classification criteria to newly proposed American College of Rheumatology criteria in a large, carefully characterised sicca cohort. Ann Rheum Dis 2014;73:31-8.

7. Harris VM, Sharma R, Cavett J, Kurien BT, Liu K, Koelsch KA, et al. Klinefelter's syndrome $(47, \mathrm{XXY})$ is in excess among men with Sjogren's syndrome. Clin Immunol 2016;168:25-9.

8. Sharma R, Harris VM, Cavett J, Kurien BT, Liu K, Koelsch KA, et al. Rare X chromosome abnormalities in systemic lupus erythematosus and Sjogren's syndrome. Arthritis Rheum 2017:69:2187-92.

9. Danda D, Sharma R, Truong D, Koelsch KA, Kurien BT, Bagavant $\mathrm{H}$, et al. Anti-La positive, anti-Ro negative subset of primary Sjogren's syndrome: anti-La is a reality but is the disease? Clin Exp Rheumatol 2017;35:438-44

10. van Bijsterveld OP. Diagnostic tests in the Sicca syndrome. Arch Ophthalmol 1969;82:10-4.

11. Whitcher JP, Shiboski CH, Shiboski SC, Heidenreich AM, Kitagawa $\mathrm{K}$, Zhang S, et al. A simplified quantitative method for assessing keratoconjunctivitis sicca from the Sjogren's Syndrome International Registry. Am J Ophthalmol 2010;149:405-15.

12. Daniels TE. Labial salivary gland biopsy in Sjogren's syndrome. Assessment as a diagnostic criterion in 362 suspected cases. Arthritis Rheum 1984;27:147-56.

13. Fisher BA, Jonsson R, Daniels T, Bombardieri M, Brown RM, Morgan $\mathrm{P}$, et al. Standardisation of labial salivary gland histopathology in clinical trials in primary Sjogren's syndrome. Ann Rheum Dis 2017;76:1161-8.

14. Shiboski SC, Shiboski CH, Criswell L, Baer A, Challacombe S, Lanfranchi H, et al. American College of Rheumatology classification criteria for Sjogren's syndrome: a data-driven, expert consensus approach in the Sjogren's International Collaborative Clinical Alliance cohort. Arthritis Care Res 2012;64:475-87. 
15. Shiboski CH, Shiboski SC, Seror R, Criswell LA, Labetoulle M, Lietman TM, et al; International Sjögren's Syndrome Criteria Working Group. 2016 American College of Rheumatology/ European League Against Rheumatism classification criteria for primary Sjögren's syndrome: A consensus and data-driven methodology involving three international patient cohorts. Ann Rheum Dis 2017;76:9-16.

16. Li H, Ice JA, Lessard CJ, Sivils KL. Interferons in Sjögren's syndrome: genes, mechanisms, and effects. Front Immunol 2013;4:290.

17. Li H, Reksten TR, Ice JA, Kelly JA, Adrianto I, Rasmussen A, et al. Identification of a Sjogren's syndrome susceptibility locus at OAS1 that influences isoform switching, protein expression, and responsiveness to type I interferons. PLoS Genet 2017;13:e1006820.

18. de Hoon MJ, Imoto S, Nolan J, Miyano S. Open source clustering software. Bioinformatics 2004;20:1453-4.

19. Saldanha AJ. Java Treeview - extensible visualization of microarray data. Bioinformatics 2004;20:3246-8.

20. Seror R, Ravaud P, Bowman SJ, Baron G, Tzioufas A, Theander E, et al. EULAR Sjogren's syndrome disease activity index: development of a consensus systemic disease activity index for primary Sjogren's syndrome. Ann Rheum Dis 2010;69:1103-9.

21. Seror R, Bowman SJ, Brito-Zeron P, Theander E, Bootsma H, Tzioufas A, et al. EULAR Sjogren's syndrome disease activity index (ESSDAI): a user guide. RMD Open 2015;1:e00022

22. Emamian ES, Leon JM, Lessard CJ, Grandits M, Baechler EC, Gaffney PM, et al. Peripheral blood gene expression profiling in Sjogren's syndrome. Genes Immun 2009;10:285-96.

23. Brito-Zeron P, Retamozo S, Gandia M, Akasbi M, Perez-De-Lis M, Diaz-Lagares C, et al. Monoclonal gammopathy related to Sjogren syndrome: a key marker of disease prognosis and outcomes. J Autoimmun 2012;39:43-8.

24. Kakugawa T, Sakamoto N, Ishimoto H, Shimizu T, Nakamura H, Nawata A, et al. Lymphocytic focus score is positively related to airway and interstitial lung diseases in primary Sjogren's syndrome. Respir Med 2018;137:95-102.
25. Risselada AP, Kruize AA, Goldschmeding R, Lafeber FP, Bijlsma JW, van Roon JA. The prognostic value of routinely performed minor salivary gland assessments in primary Sjogren's syndrome. Ann Rheum Dis 2014;73:1537-40.

26. Haldorsen K, Moen K, Jacobsen H, Jonsson R, Brun JG. Exocrine function in primary Sjogren syndrome: natural course and prognostic factors. Ann Rheum Dis 2008;67:949-54.

27. Bookman AA, Shen H, Cook RJ, Bailey D, McComb RJ, Rutka JA, et al. Whole stimulated salivary flow: correlation with the pathology of inflammation and damage in minor salivary gland biopsy specimens from patients with primary Sjogren's syndrome but not patients with sicca. Arthritis Rheum 2011;63:2014-20.

28. Carubbi F, Alunno A, Cipriani P, Bartoloni E, Baldini C, Quartuccio $\mathrm{L}$, et al. A retrospective, multicenter study evaluating the prognostic value of minor salivary gland histology in a large cohort of patients with primary Sjogren's syndrome. Lupus 2015;24:315-20.

29. Maier-Moore JS, Koelsch KA, Smith K, Lessard CJ, Radfar L, Lewis D, et al. Antibody-secreting cell specificity in labial salivary glands reflects the clinical presentation and serology in patients with Sjogren's syndrome. Arthritis Rheum 2014;66:3445-56.

30. Tengner P, Halse AK, Haga HJ, Jonsson R, Wahren-Herlenius M. Detection of anti-Ro/SSA and anti-La/SSB autoantibody-producing cells in salivary glands from patients with Sjogren's syndrome. Arthritis Rheum 1998;41:2238-48.

31. Davidson BK, Kelly CA, Griffiths ID. Primary Sjogren's syndrome in the North East of England: A long-term follow-up study. Rheumatology 1999;38:245-53.

32. Teppo H, Revonta M. A follow-up study of minimally invasive lip biopsy in the diagnosis of Sjogren's syndrome. Clin Rheumatol 2007;26:1099-103.

33. Al-Hashimi I, Wright JM, Cooley CA, Nunn ME. Reproducibility of biopsy grade in Sjogren's syndrome. J Oral Pathol Med 2001;30:408-12. 